\title{
Development of an efficient glucosinolate extraction method
}

\author{
T. Doheny-Adams*, K. Redeker, V. Kittipol, I. Bancroft and S. E. Hartley
}

\begin{abstract}
Background: Glucosinolates, anionic sulfur rich secondary metabolites, have been extensively studied because of their occurrence in the agriculturally important brassicaceae and their impact on human and animal health. There is also increasing interest in the biofumigant properties of toxic glucosinolate hydrolysis products as a method to control agricultural pests. Evaluating biofumigation potential requires rapid and accurate quantification of glucosinolates, but current commonly used methods of extraction prior to analysis involve a number of time consuming and hazardous steps; this study aimed to develop an improved method for glucosinolate extraction.

Results: Three methods previously used to extract glucosinolates from brassicaceae tissues, namely extraction in cold methanol, extraction in boiling methanol, and extraction in boiling water were compared across tissue type (root, stem leaf) and four brassicaceae species (B. juncea, S. alba, R. sativus, and E. sativa). Cold methanol extraction was shown to perform as well or better than all other tested methods for extraction of glucosinolates with the exception of glucoraphasatin in R. sativus shoots. It was also demonstrated that lyophilisation methods, routinely used during extraction to allow tissue disruption, can reduce final glucosinolate concentrations and that extracting from frozen wet tissue samples in cold 80\% methanol is more effective.
\end{abstract}

Conclusions: We present a simplified method for extracting glucosinolates from plant tissues which does not require the use of a freeze drier or boiling methanol, and is therefore less hazardous, and more time and cost effective. The presented method has been shown to have comparable or improved glucosinolate extraction efficiency relative to the commonly used ISO method for major glucosinolates in the Brassicaceae species studied: sinigrin and gluconasturtiin in B. juncea; sinalbin, glucotropaeolin, and gluconasturtiin in S. alba; glucoraphenin and glucoraphasatin in $R$. sativus; and glucosatavin, glucoerucin and glucoraphanin in E. sativa.

\section{Background}

Glucosinolates, B-thioglucoside $N$-hydroxysulfate derivatives, are secondary metabolites found in brassicaceae and related families [1]. Over 120 glucosinolates, which differ in variable aglycone side chains derived from an alpha-amino acid, have been identified and classified into aliphatic, aromatic and indole glucosinolates [2, 3]. Due to their prevalence in cultivated vegetables, spices, oils and animal feed, glucosinolates and their hydrolysis products have been much studied in the context of their effects on human and animal nutrition $[4,5]$. Glucosinolates and their breakdown products have also been a

*Correspondence: tim.doheny-adams@york.ac.uk Department of Biology, University of York, Wentworth Way, York YO10 5DD, UK focus of studies in dietary prevention of disorders linked to oxidative stress such as cancer and gastric ulcers $[2,6$, 7] and more recently, potential undesirable dietary effects such as genotoxicity of glucosinolate breakdown products in broccoli [8] and Pak Choi [9]. The breakdown of glucosinolates has also been studied because of their potential use as agricultural pesticides in a technique known as biofumigation. In biofumigation a glucosinolate-rich crop is mulched into the field, releasing toxic secondary glucosinolate by-products, in order to reduce the incidence of pests, weeds and diseases in the following arable and horticultural crops [10-13].

Evaluating biofumigation potential requires rapid and accurate quantification of glucosinolates, but current commonly used methods of extraction prior to analysis involve a number of time consuming and potentially 
hazardous steps. These steps are (1) lyophilisation, or freeze drying, and tissue disruption, (2) extraction in water or methanol, (3) purification of extract, typically by desulfation on DEAE Sephadex, and (4) separation and analysis of (desulfo)glucosinolates. These steps are outlined in Fig. 1 and discussed in more depth below. This study aimed to improve glucosinolate extraction methods by finding alternatives to commonly used steps which are unnecessary or likely to introduce variability.

Myrosinase, an enzyme found in brassicaceae and compartmentalised in cells in close proximity to glucosinolates, is responsible for hydrolysing glucosinolates upon plant tissue disruption. Accurate analysis of glucosinolates therefore requires inactivation of myrosinase prior to tissue disruption. This is achieved by first freezing then freeze drying the tissue which allows disruption by milling or grinding to occur in the absence of water (Fig. 1). Lyophilisation, or freeze drying, is used to remove water from glucosinolate-containing tissues while preventing myrosinase mediated glucosinolate hydrolysis through thermal inhibition. Publications on freeze drying plant tissue have focussed primarily on the production of heat or its implications in generating oxygen sensitive foodstuffs (e.g. space, military or extreme-sport foodstuffs and instant coffee) [14]. To our knowledge, no study has yet examined the efficiency of freeze drying in maintaining glucosinolate concentrations. Freeze drying functions on the principle of sublimation: pressure is reduced below the triple point of water $\left(6.12 \mathrm{mbar}, 0.01{ }^{\circ} \mathrm{C}\right)$ at which point sublimation of ice from the sample occurs. The cooling effect of sublimation should be high enough to ensure the sample remains below $0{ }^{\circ} \mathrm{C}$ for the initial stage of freeze drying, thus minimizing enzyme-driven glucosinolate hydrolysis. Rapid sample loading and rapid initial pressure drop are also required to avoid sample defrosting before pressure is reduced below 6.12 mbar. Leaves have a high surface area to volume ratio and may defrost quickly, activating myrosinase and reducing final glucosinolate concentration. Despite the importance of the freeze drying process in glucosinolate extraction, many authors do not report details which are likely to affect final concentrations of glucosinolates (e.g. how samples are transported, temperature of the room, whether a heating/cold plate is used and time taken for the pressure to drop).

The most commonly used methods for extraction of glucosinolates from plant material are based on the ISO 9167-1 method [15; highlighted in grey in Fig. 1], which was designed for extraction of glucosinolates from $B$. napus seed and has been adapted to suit the needs of researchers examining glucosinolate profiles of other plant species and tissue types. Although freeze drying is not explicitly detailed in the ISO 9167-1 method, it is an implicit requirement in order to avoid myrosinase mediated glucosinolate hydrolysis during disruption of leaf, stem or root tissues. Once the plant tissue is prepared, the ISO $9167-1$ extraction is carried out at $75{ }^{\circ} \mathrm{C}$ in $70 \%$ methanol for $10 \mathrm{~min}$. Heating the sample is thought to be an essential step to denature myrosinase, thus preventing enzymatic hydrolysis of glucosinolates [16]. Samples are

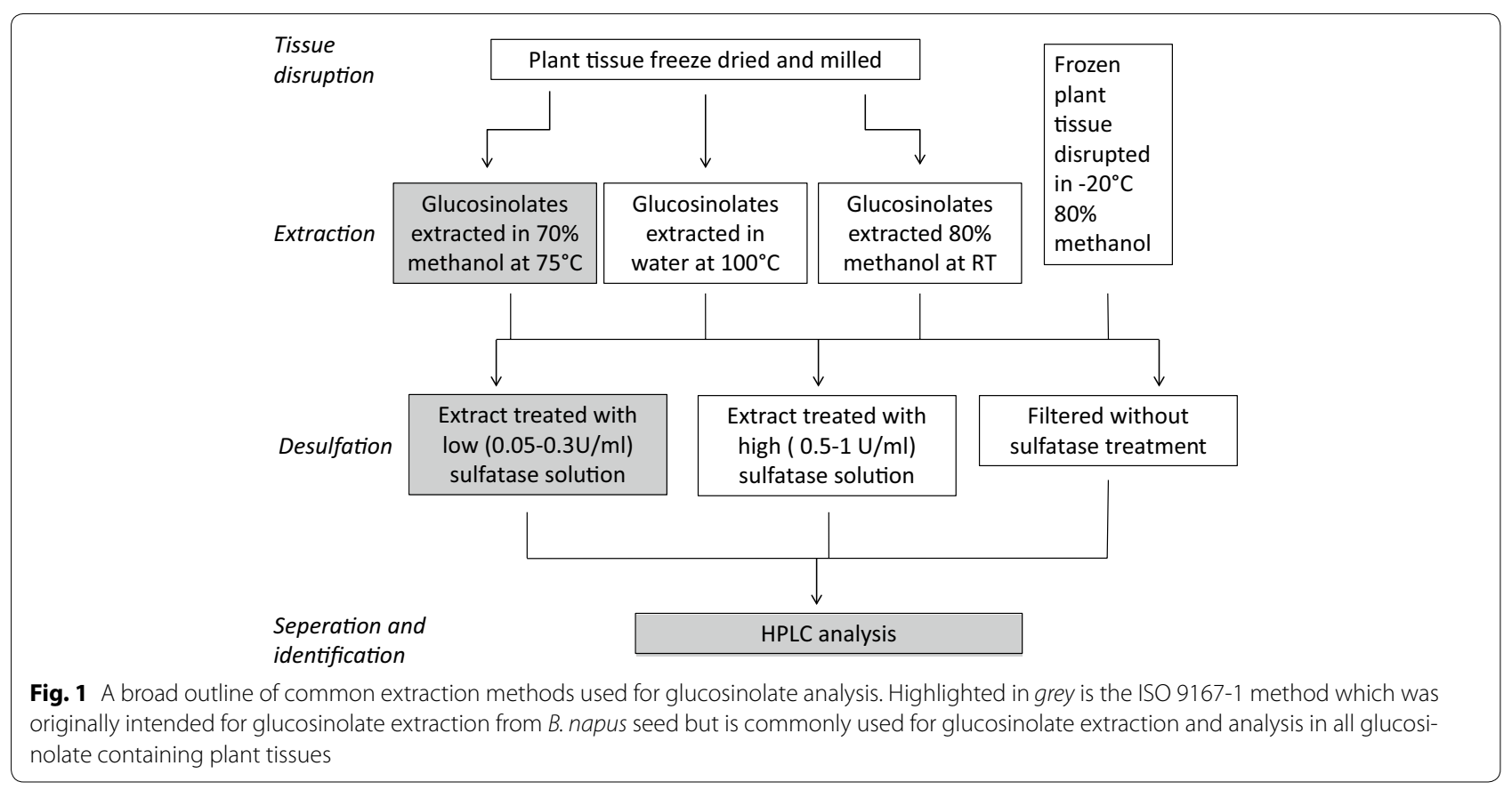


subsequently desulfated by ion exchange chromatography on a DEAE Sephadex column to remove impurities. Desulfoglucosinolates are then separated and identified using HPLC with a reverse phase C18 column and a UV or MS detector. Hazards associated with boiling methanol [17] and the time required for extractions using this method have led researchers to seek alternatives. Replacing heated methanol with boiling water is reported to have comparable [18, 19], and in some cases better [20], extraction efficiencies. Although most glucosinolates are thermostable for the typical 10-30 min heating period, indole glucosinolates such as 4-hydroxy-glucobrassicin and 4-methoxyglucobrassicin have been reported to degrade quickly at temperatures below $100{ }^{\circ} \mathrm{C}$ [21]. In addition, prior to 2002 the major glucosinolate in leaves of E. sativa, 4-mercaptobutyl glucosinolate, was missed because it self-dimerises via formation of disulphide linkages during extraction [22]. A major challenge therefore to ensuring consistent and repeatable GSL analysis is to create extraction conditions in which myrosinase is inactive, and glucosinolates do not self-react or degrade. A single study, conducted exclusively on radish roots, has demonstrated that cold extraction in $80 \%$ methanol does not cause appreciable reduction in glucosinolate concentrations compared to more conventional heated extraction methods [23]. However, myrosinase activity can vary dramatically [24] and whether this method is suitable for extraction of glucosinolates from other glucosinolate containing plants has not previously been assessed.

A desulfation step is often carried out post extraction to purify desulfoglucosinolates and improve accuracy and identification from HPLC. However, the desulfation reaction of glucosinolates can be affected by feedback inhibition of the enzyme which causes incomplete desulfation of glucosinolates [25]. In addition, rhamnopyranosyloxybenzyl glucosinolates extracted from $M$. oleifera have been shown to be completely converted and degraded by the desulfation purification step [26]. Due to these drawbacks, and the additional time and potential error extra steps can introduce, some authors have skipped the purification and desulfation steps entirely [19, 26, 27] (Fig. 1).

We have tested each stage of glucosinolate analysis from the roots, stems and leaves of $B$. juncea, S. alba, $R$. sativus, E. sativa and $B$. napus and suggest a number of adjustments/improvements which can be made to reduce the costs, time and variability associated with glucosinolate analysis. Specifically, this study aims to address the following questions:

1) How do lyophilisation conditions affect glucosinolate concentrations?

2) Is lyophilisation a necessary step for glucosinolate extraction from green tissues?
3) Do extractions in hot methanol, cold methanol and boiling water yield comparable glucosinolate concentrations across a range of brassicaceae species and tissue types?

4) How do desulfation time and enzyme concentration affect final glucosinolate concentrations?

5) Is desulfation a necessary step for glucosinolate extraction from green tissue?

\section{Methods}

\section{Plant material}

B. napus used in the freeze drying tests were grown in $1 \mathrm{~L}$ pots filled with Terra-green in a controlled temperature glasshouse (regulated from 17.6 to $27.7^{\circ} \mathrm{C}$ ). At $3-4$ weeks post germination, leaves were removed and halved down the limits of the midrib, excluding the midrib from the final sample. Leaf halves were immediately frozen in liquid nitrogen and stored at $-80{ }^{\circ} \mathrm{C}$ for a maximum of 1 week.

B. juncea (cv. ISCI99), R. sativus (cv. Bento), S. alba (cv. Ida Gold) and E. sativa (cv. Nemat) plants were grown by Barworth agriculture ltd. in a sandy loam soil dominated fields (coordinates: 53.000371, -0.290404) from $31 / 07 / 2014$ to $25 / 09 / 2014$. Total stem and total leaves were cut from flowering plants and immediately frozen in liquid nitrogen; root samples were gently washed and dried before freezing in liquid nitrogen. Samples were stored at $-80^{\circ} \mathrm{C}$ for a maximum of 2 months.

\section{Freeze drying}

Samples wrapped loosely in aluminium foil were transported on dry ice and loaded into one of two freeze driers (Table 1). Maximum loading time was $30 \mathrm{~s}$.

\section{Tissue disruption}

(i) Freeze dried plant tissue was homogenised to a roughly ground powder (approximately $0.1 \mathrm{~cm}$ particle size) using a grinder (Lloytron, E5601BK) Homogenised ground samples were milled at a frequency of $20 \mathrm{~Hz}$ for $10 \mathrm{~min}$ (Retch, MM400) with 2 steel ball bearings to a fine powder (particle diameter $<0.1 \mathrm{~mm}$ ). Samples were then sealed and stored at $20^{\circ} \mathrm{C}$ for up to 9 months.

(ii) Frozen fresh B. napus leaf halves (experiment 2, Table 2) were placed in $2 \mathrm{ml}$ eppendorf vials and stored at $-20{ }^{\circ} \mathrm{C}$. $1.755 \mathrm{ml}$ of $80 \%$ methanol precooled at $-20^{\circ} \mathrm{C}, 25 \mu \mathrm{l}$ of $5 \mathrm{mM}$ sinigrin and 2 small ball bearings were added. Samples were milled for $10 \mathrm{~min}$ at frequency $20 \mathrm{~Hz}$ (TissueLyser II, Qiagen). Final concentrations of methanol were estimated by incorporating average leaf moisture content of fresh B. napus leaves according to Eq. (1). Final concentration of methanol ranged from 79.3 to $79.9 \%$ and leaf 
Table 1 Freeze drier characteristics

\begin{tabular}{|c|c|c|c|c|c|c|}
\hline Freeze drier & Room temp $\left({ }^{\circ} \mathrm{C}\right)$ & Cooling plate & Time to $5 \mathrm{mbar}(\mathrm{s})$ & $\begin{array}{l}\text { Lowest pressure } \\
\text { (mbar) }\end{array}$ & $\begin{array}{l}\text { Freezer temperature } \\
\left({ }^{\circ} \mathrm{C}\right)\end{array}$ & Model \\
\hline A & 22 & Yes & 90 & 0.12 & -45 & $\begin{array}{l}\text { Lyotrap, LTE scientific Itd. } \\
1 \text { chamber }\end{array}$ \\
\hline B & 28 & No & 65 & 0.16 & -53 & $\begin{array}{l}\text { Thermo, Heto Powerdry } \\
\text { LL3000 } \\
4-6 \text { chambers }\end{array}$ \\
\hline
\end{tabular}

Table 2 Summary of methods used

\begin{tabular}{|c|c|c|c|c|c|c|c|}
\hline Experiment & Fig & Species & Tissue & $\begin{array}{l}\text { Freeze drying/tis- } \\
\text { sue disruption }\end{array}$ & Extraction & Desulfation & HPLC \\
\hline $\begin{array}{l}\text { 1-Effect of freeze } \\
\text { drier on GSL con- } \\
\text { centration }\end{array}$ & 2 & B. napus & Leaves & FD-A or FD-B/mill & Cold methanol & $0.3 \mathrm{U} / \mathrm{ml}$ for $24 \mathrm{~h}$ & ISO 9167-1 method \\
\hline $\begin{array}{l}\text { 2-Comparison of } \\
\text { GSL extraction from } \\
\text { freeze dried tissue } \\
\text { with extraction } \\
\text { from wet tissue }\end{array}$ & 3 & B. napus & Leaves & $\begin{array}{l}\mathrm{FD}-\mathrm{A} \text { or }-20^{\circ} \mathrm{C} \\
\text { methanol }\end{array}$ & Cold methanol & $0.3 \mathrm{U} / \mathrm{ml}$ for $24 \mathrm{H}$ & ISO 9167-1 method \\
\hline $\begin{array}{l}\text { 3-Comparison of } \\
\text { extraction methods }\end{array}$ & 6,7 & $\begin{array}{l}\text { R. sativus } \\
\text { B. juncea } \\
\text { S. alba } \\
\text { E. sativa }\end{array}$ & Leaves, stems, roots & FD-A & $\begin{array}{l}\text { Hot methanol, } \\
\text { Cold methanol, } \\
\text { Boiling water }\end{array}$ & $0.3 \mathrm{U} / \mathrm{ml}$ for $24 \mathrm{H}$ & ISO 9167-1 method \\
\hline $\begin{array}{l}\text { 4-Comparison of } \\
\text { desulfation/purifi- } \\
\text { cation methods }\end{array}$ & 8,9 & $\begin{array}{l}\text { R. sativus } \\
\text { B. juncea } \\
\text { S. alba } \\
\text { E. sativa }\end{array}$ & Leaves, stems, roots & FD-A & Cold methanol & $\begin{array}{l}0.3 \mathrm{U} / \mathrm{ml} \text { for } 12,24 \\
48 \mathrm{~h} \text {, and } 5 \mathrm{U} / \mathrm{ml} \text { for } \\
16 \mathrm{~h} \text { or filtration }\end{array}$ & $\begin{array}{l}\text { ISO 9167-1 method for } \\
\text { desulfoGSL, } \\
\text { Herzallah and Holly } \\
\text { method for intact } \\
\text { GSLs }\end{array}$ \\
\hline
\end{tabular}

moisture content accounted for $<1 \%$ of final liquid volume.

$$
\mathrm{C}_{\mathrm{MeOHf}}=\frac{c_{\mathrm{MeOHi}} \times V_{\mathrm{MeOHi}}}{m_{a v} \times m_{d l}+V_{\mathrm{MeOHi}}}
$$

where $\mathrm{c}_{\mathrm{MeOHf}}$ is final methanol concentration (\%), $\mathrm{c}_{\mathrm{MeOHi}}$ is initial methanol concentration $(90 \%), \mathrm{V}_{\mathrm{MeOHi}}$ is initial methanol volume $(1.755 \mathrm{ml}), \mathrm{m}_{\mathrm{av}}$ is the average moisture content per dry weight (in this case $0.22 \mathrm{ml} / \mathrm{g}$ ), $\mathrm{m}_{\mathrm{dl}}$ dry mass of leaf sample (g).

\section{Glucosinolate extraction}

Extractions were carried out in one of three ways (Fig. 1). In each case $50 \mu \mathrm{l}$ of a $5 \mathrm{mM}$ gluctropaeolin (for B. juncea samples) or $20 \mathrm{mM}$ sinigrin (for all other samples) internal standard was added.

\section{Hot methanol extraction (based on the ISO 9167-1 method)} $0.1 \mathrm{~g}$ of plant material was preheated at $75^{\circ} \mathrm{C}$ for $3 \mathrm{~min}$ in a $20 \mathrm{ml}$ falcon tube. $4.95 \mathrm{ml}$ of 70:30 methanol:water, preheated to $75^{\circ} \mathrm{C}$ and the internal standard was added. The sample was incubated at $75{ }^{\circ} \mathrm{C}$ for 10 min, and manually shaken every $2 \mathrm{~min}$. The sample was then centrifuged at $4000 \mathrm{rpm}$ (Jouan, model:B 3.11) for $10 \mathrm{~min}$. Supernatent was stored at $-20{ }^{\circ} \mathrm{C}$ or desulfated directly.

\section{Cold methanol extraction (Ishida et al. [23])}

$5 \mathrm{ml}$ of $80: 20$ methanol:water at $20^{\circ} \mathrm{C}$ was added to $0.1 \mathrm{~g}$ plant tissue and the internal standard was added. The sample was shaken and left to stand for $30 \mathrm{~min}$ at room temperature. The sample was then mixed at $70 \mathrm{rpm}$ with a platform rocker for a further $30 \mathrm{~min}$ (Bibby, STR6) before centrifugation at $4000 \mathrm{rpm}$ (Jouan, model:B 3.11) for $10 \mathrm{~min}$. Supernatent was then filtered through a $0.22 \mu \mathrm{m}$ syringe filter (Millex GP) for direct injection on HPLC, or unfiltered if applied to Sephadex column in a purification step.

\section{Boiling water extraction (adapted from Herzallah and Holley [19])}

$25 \mathrm{ml}$ of boiling water was added to $0.1 \mathrm{~g}$ of freeze dried and milled plant tissue in a $150 \mathrm{ml}$ erlenmeyer flask and the internal standard was added. Sample was heated at $100{ }^{\circ} \mathrm{C}$ and stirred with a magnetic stirrer hot plate for 
10 min. Sample was heated for a further $4 \mathrm{~h}$ at $70{ }^{\circ} \mathrm{C}$ before centrifugation at $4000 \mathrm{rpm}$ (Jouan, model:B 3.11) for $10 \mathrm{~min}$. Sample was topped up to $20 \mathrm{ml}$ with deionised water.

\section{Purification and determination of activity of sulfatase} Sulfatase from Helix pomatia type H-1 (Sigma, S9626) was purified according to Wathalet et al. [25]. $25 \mathrm{mg}$ of sulfatase was added to $1 \mathrm{ml} 40 \%$ ethanol and centrifuged at $8000 \mathrm{rmp}$ for $1 \mathrm{~min}$ (eppendorf centrifuge, 54,151). The supernatant was transferred to a fresh $2 \mathrm{ml}$ eppendorf tube, $1 \mathrm{ml}$ of pure ethanol was added to precipitate the sulfatase before being centrifuged at $8 \mathrm{krmp}$ for $1 \mathrm{~min}$. The supernatant was discarded and the sulfatase pellet air dried and redissolved in $2 \mathrm{ml}$ of water.

Activity of sulfatase was determined based on the ISO 9167-1 method. $1 \mathrm{ml}$ of buffered $0.15 \mathrm{mM}$ sinigrin solution $(3 \mathrm{ml}$ of $5 \mathrm{mM}$ sinigrin, adjusted to $100 \mathrm{ml}$ with a solution containing $40 \mathrm{ml} 0.2 \%$ ethylene diamine, $73 \mathrm{ml}$ $0.2 \%$ acetic acid; adjusted to $\mathrm{pH} 5.8$ ) in a quartz cuvette was placed in a UV spectrometer set to $229 \mathrm{~nm}$. At $\mathrm{t}=0,25 \mu \mathrm{l}$ of diluted and undiluted purified sulfatase was added to the cuvette and measurements taken over the course of $4 \mathrm{~h}$. The tangent to $\mathrm{t}=0$ was plotted and its gradient $(\Delta \mathrm{A} / \Delta \mathrm{t})$ measured. Activity was calculated using Eq. (2):

$$
\operatorname{Activity}(\mathrm{U} / \mathrm{ml})=\frac{\Delta A \times 5.7}{\Delta t A_{e}}
$$

where $\Delta \mathrm{A} / \Delta \mathrm{t}$ is the gradient at $\mathrm{t}=0$ and $\mathrm{A}_{\mathrm{e}}$ is the difference between absorbance at equilibrium and absorbance at $\mathrm{t}=0$.

The activity for Sulfatase from Helix pomatia type H-1 (Sigma, S9626) given by the supplier is determined by desulfation of p-nitrocatechol sulfate and is an order of magnitude higher than the activity measured for desulfation of sinigrin using this method.

\section{Desulfation of glucosinolates}

As per the ISO 9067-1 method, columns were prepared with $0.5 \mathrm{ml}$ Sephadex slurry (2 g DEAE Sephadex beads in $30 \mathrm{ml} 2 \mathrm{M}$ acetic acid.) and activated with $2 \mathrm{ml}$ imizadole formate $(6 \mathrm{M})$. Columns were washed twice with $1 \mathrm{ml}$ water. The column was washed twice with $1 \mathrm{ml} 20 \mathrm{mM}$ sodium acetate $(\mathrm{pH} 4.0)$ and $75 \mu \mathrm{l}$ of purified sulfatase was added ( 5 or $0.3 \mathrm{U} / \mathrm{ml}$ ). Columns were incubated at room temperature for either 12, 24 or $48 \mathrm{~h}$ before elution of desulfoglucosinolates with two $1 \mathrm{ml}$ volumes of water. For the reduction of disulphide linkages, from dimerized desulfoglucosatavin in E. sativa extracts $3 \mathrm{~g}$ TCEP (Tris(2-carboxyethyl)phosphine hydrochloride powder Sigma, C4706) was added to $1 \mathrm{ml}$ of desulfated extract. Desulfoglucosinolates were stored at $-20{ }^{\circ} \mathrm{C}$ before high performance liquid chromatography analysis (Additional file 1).

For the high sulfatase treatment, between 0.5 and $1 \mathrm{ml}$ of sample was added due to insufficient sample volume remaining.

\section{HPLC}

A Waters 600E system controller attached to a Waters 717 autosampler, Waters 996 photodiode array detector and SphereClone $5 \mu$ ODS(2) column (Phenomonex) were used for separation and detection of desulfo and intact glucosinolates.

\section{HPLC analysis of desulfoglucosinolates-adapted from ISO 9167-1}

A reverse phase C18 column (Phenomonex, SphereClone $5 \mu$ ODS(2), $150 \mathrm{~mm} \times 4.6 \mathrm{~mm}$ ) was equilibrated for 30 min with a mobile phase which consisted of $100 \%$ $\mathrm{diH}_{2} \mathrm{O}$. Flow rate was set to $1 \mathrm{ml} / \mathrm{min}$ and samples separated according to programme for desulfoglucosinolates detailed in Table 3. Mobile phase solutions were degassed for $30 \mathrm{~min}$ in a sonicator (Decon, Sussex England).

Solution A: $100 \% \mathrm{diH}_{2} \mathrm{O}$

Solution B: 70:30, $\operatorname{diH}_{2} \mathrm{O}$ :acetonitrile

Desulfoglucosinolates were quantified using $229 \mathrm{~nm}$ wavelength within the UV spectrum. The HPLC PDA detector allowed a full spectrum analysis from 180 to $800 \mathrm{~nm}$, allowing comparative UV-visible spectra analysis, which aided in identifying unknown glucosinolates. Through standard injections and HPLC-MS identification we were able to confirm the id's of these reported glucosinolates. Desulfated purified standards: sinigrin (sigma aldrich), glucotropaeolin, glucoraphenin, glucoraphanin, glucerucin, glucobrassicin, gluconasturtiin, sinalbin, progoitrin and glucoiberin (phytoplan).

\section{Mass spectrometry}

Major glucosinolates for which no commercial standard is available were identified using an MS detector (Bruker maXis UHR-TOF) with the following settings:

Table 3 Mobile phase conditions for separation of desulfoglucosinolates

\begin{tabular}{lccl}
\hline Time & \% Solution A & \% Solution B & Transition \\
\hline 0 & 100 & 0 & \\
30 & 0 & 100 & Linear gradient \\
35 & 0 & 100 & \\
40 & 100 & 0 & Linear gradient \\
50 & 100 & 0 & \\
\hline
\end{tabular}


Source: Standard electrospray (flow split 1/10 from LC) Nebulizer: 2.0 bar

Dry gas: $6.0 \mathrm{~L} / \mathrm{min}$

Dry gas heater: $25^{\circ} \mathrm{C}$

Capillary voltage: $3500 \mathrm{~V}$

Ion polarity: positive

Spectra rate: $1 \mathrm{~Hz}$

\section{HPLC analysis of intact glucosinolates-adapted from Herzallah and Holly [19]}

A C18 column (Phenomonex, SphereClone $5 \mu$ ODS(2)) was equilibrated for $3 \mathrm{~h}$ with a mobile phase which consisted of $80 \mathrm{~mL}(0.02 \mathrm{M})$ TBA (tetrabutylammonium bromide) and $20 \mathrm{~mL}$ ACN (acetonitrile) with detection at $229 \mathrm{~nm}$. The flow rate was set at $1.0 \mathrm{ml} / \mathrm{min}$ and separated according to programme for desulfoglucosinolates detailed in Table 3.

Solution A: 100\% TBA (0.02 M)

Solution B: 70:30, TBA (0.02 M):acetonitrile

Glucosinolates were quantified using the chromatogram from $229 \mathrm{~nm}$ and standard curves were constructed using pure sinigrin (sigma aldrich), glucotropaeolin, glucoraphenin, glucoraphanin, glucerucin, glucobrassicin, gluconasturtiin, sinalbin, progoitrin and glucoiberin (phytoplan).

In the case of glucoraphasatin in $R$. sativus leaves and glucotropaeolin in $B$. juncea minor alterations were made to avoid peaks co-eluting. The mobile phase programme for R. sativus leaves was $100 \%$ A for $5 \mathrm{~min}$, followed by a 35 min linear gradient to $66 \%$ B followed by a 5 min linear gradient to $100 \%$ B followed by a 5 min linear gradient to $100 \%$ A. For B. juncea leaves, an isocratic $85: 15$, TBA $(0.02 \mathrm{M})$ :acetonitrile mobile phase for $70 \mathrm{~min}$ was used.

\section{Determination of myrosinase activity}

Activity of pure myrosinase was tested in water and $80 \%$ methanol solutions containing $0.25 \mathrm{mM}$ sinigrin and $0.1 \mathrm{mM}$ ascorbic acid, a myrosinase cofactor [30]. Myrosinase was added at $\mathrm{t}=0$ and absorbance of sinigrin at $229 \mathrm{~nm}$ was measured over the course of an hour. Activity was measured at room temperature $\left(25^{\circ} \mathrm{C}\right)$.

\section{Determination of glucosinolate thermostability}

A $50 \mu \mathrm{l}$ of $10 \mathrm{mM}$ sinigrin, $10 \mathrm{mM}$ glucotropaeolin, $10 \mathrm{mM}$ glucobrassicin solution was added to $0.95 \mathrm{ml}$ water or $70 \%$ methanol preheated to 100 or $75{ }^{\circ} \mathrm{C}$ respectively and sealed in $1.5 \mathrm{ml}$ eppendorf tubes. Samples were maintained at either 100 or $75^{\circ} \mathrm{C}$ for $5,10,30$ and $60 \mathrm{~min}$ and intact glucosinolate concentrations analysed with
HPLC following the adapted Herzallah and Holly method [19].

\section{Calculation of glucosinolate content}

Glucosinolate content, expressed in $\mu \mathrm{mol} / \mathrm{g}$ were calculated according to the ISO 9067-1 method (Eq. 3):

Glucosinolate content $=\frac{A_{g}}{A_{s}} \times \frac{n}{m} \times K_{g} \times \frac{100}{100-w}$

where $\mathrm{A}_{\mathrm{g}}$ is the peak area corresponding to desulfoglucosinolate; $A_{s}$ is the peak area corresponding to internal standard; $\mathrm{n}$ is the quantity, in micromoles, of the internal standard; $m$ is the mass of the test portion; $K_{g}$ is the response factor of the desulfoglucosinolate relative to the internal standard; $\mathrm{w}$ is the moisture and volatile matter content, expressed as a percentage by mass of the test sample.

\section{Statistical analysis}

Paired two tailed $t$ test analysis were carried out on total $B$. napus glucosinolate content per leaf half in experiments 1 and 2 with Microsoft excel (Table 2). For determination of significance of effect of method on final glucosinolate content estimates in experiments 3 and 4 (Table 2), repeat measure ANOVA analyses were carried out for each glucosinolate with $\mathrm{R}$ statistical software package (version 3.3.1).

\section{Results and discussion Lyophilisation}

Modifications to the ISO9167-1 method (specifically created for the extraction and analysis of glucosinolates from oil rape seed samples) are required for analysis of plant green tissues (leaves, stems and roots). A number of prior-to-analysis steps, such as sampling in the field, cleaning (if required), freezing, crushing, storage or/and shipping and reduction of sample amount have been discussed by Wathelet et al. [28] and are not revisited here. These preliminary steps are followed by lyophilisation, or freeze drying, to remove water from glucosinolate containing tissues while preventing myrosinase mediated glucosinolate hydrolysis through thermal inhibition. This process allows subsequent tissue disruption without risking glucosinolate degradation.

We tested reproducibility of glucosinolate concentrations extracted after lyophilisation in separate freeze driers (Table 4). Fresh B. napus leaves were halved, loosely wrapped in foil, flash frozen in liquid nitrogen and transported in dry ice to be dried in separate freeze driers (Table 4). Total glucosinolate concentrations were significantly higher in samples dried in freeze drier A than freeze drier B (Fig. 2a). In addition, samples dried 
Table 4 Freeze drier characteristics

\begin{tabular}{llllll}
\hline $\begin{array}{l}\text { Freeze } \\
\text { drier }\end{array}$ & $\begin{array}{l}\text { Room } \\
\text { temp }\left({ }^{\circ} \mathrm{C}\right)\end{array}$ & $\begin{array}{l}\text { Cooling } \\
\text { plate }\end{array}$ & $\begin{array}{l}\text { Time } \\
\text { to } 5 \text { mbar } \\
(\mathbf{s})\end{array}$ & $\begin{array}{l}\text { Lowest } \\
\text { pressure } \\
\text { (mbar) }\end{array}$ & $\begin{array}{l}\text { Freezer } \\
\text { tem- } \\
\text { perature } \\
\left({ }^{\circ} \mathbf{C}\right)\end{array}$ \\
\hline A & 22 & Yes & 90 & 0.12 & -45 \\
B & 28 & No & 65 & 0.16 & -53 \\
\hline
\end{tabular}

in freeze drier B developed a darker hue and deformed more than samples in dried in freeze drier A (Fig. 2b). Plant tissue samples have been shown to deform during the freeze drying process when temperatures exceed the glass transition state and melting point of water [29]. It is likely that samples placed into freeze drier B may have defrosted before the pressure had reduced below the 6.12 mbar required for sublimation due to higher temperatures and the lack of cooling plate. As a result, enzyme mediated hydrolysis of glucosinolates may have occurred at the initial stage. Additionally, as sublimation slows over time due to the remaining water vapour passing through a dry layer of increasing thickness and because water is increasingly more tissue bound, the sample temperature may have increased to above $0{ }^{\circ} \mathrm{C}$ in freeze drier B, causing defrosting.

These results underline the need for a more substantive study to assess optimal conditions for freeze drying plant tissues for glucosinolate analysis. It is clear that differences in freeze drying can introduce significant variability in retained glucosinolate concentrations (Fig. 2a).

A cold methanol extraction method may be sufficient to (1) inactivate myrosinase and (2) efficiently extract glucosinolates, precluding the need for the lyophilisation step altogether. We tested this by comparing glucosinolates extracted from one half of a B. napus leaf in $80 \%$ methanol without freeze drying against glucosinolates extracted from the other half, first dried in freeze drier A and then extracted using the cold methanol extraction method.

No significant difference in final glucosinolate concentration was found between the two methods (Fig. 3). Freeze drying is an energy intensive and costly process requiring long drying times under continuous vacuum and the significant effect of freeze drier parameters on final glucosinolate concentrations (Fig. 2a) highlights a potential source of variation between studies. If long term storage of plant tissue samples is not required, skipping the freeze drying step and extracting glucosinolates directly into cold methanol $\left(-20{ }^{\circ} \mathrm{C}\right)$ is cheaper, quicker and less hazardous.

\section{Extraction}

Some authors have highlighted that glucosinolates, specifically indole glucosinolates, are heat sensitive and are significantly degraded in temperatures $\geq 75^{\circ} \mathrm{C}$ in $<10 \mathrm{~min}$ [21]. This has serious implications for accuracy and reliability of the ISO 9167-1 extraction method, which recommends extractions occur in boiling $70 \%$ methanol $\left(75^{\circ} \mathrm{C}\right)$ for $10 \mathrm{~min}$, as well as the less commonly used boiling water extraction $\left(100{ }^{\circ} \mathrm{C}\right)$. In order to first test whether thermal degradation of glucosinolates was likely to occur with these methods we measured the glucosinolate concentrations of pure sinigrin (aliphatic), glucotropaeolin (aromatic) and glucobrassicin (indole) in boiling water (Fig. 4) and boiling 70\% methanol (data not shown). Sinigrin and glucotropaeolin did not significantly decrease over 60 min suggesting that extraction in boiling water or methanol is unlikely to affect the concentrations of these glucosinolates. However, glucobrassicin was thermally degraded at $100{ }^{\circ} \mathrm{C}$ and data from extractions carried out at these temperatures or above (such as with microwave based methods) may underestimate the concentration of a

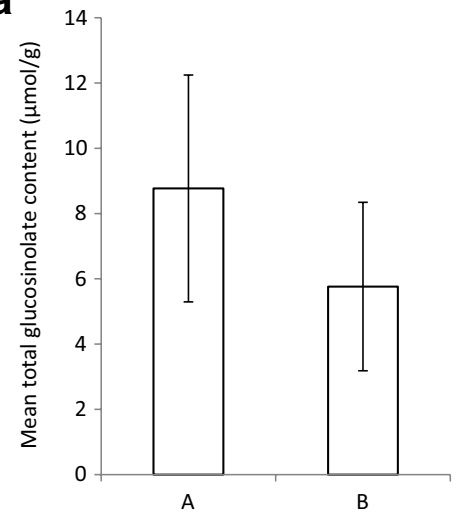

b

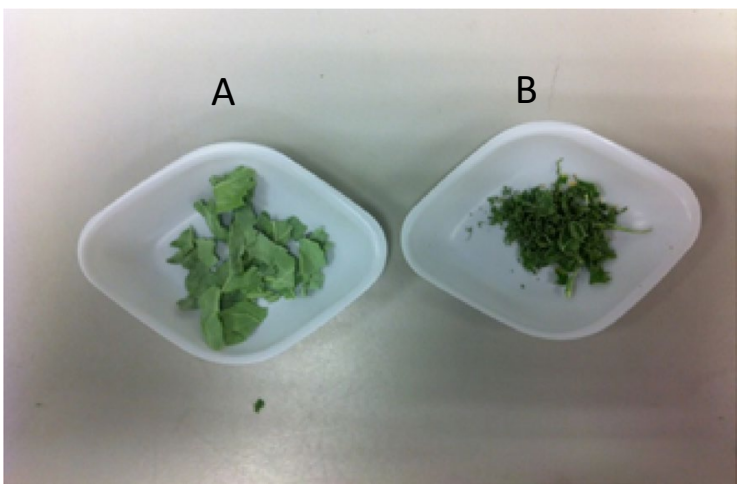

Fig. 2 a Total glucosinolate concentration of $B$. napus leaf halves dried in freeze drier $B$ are significantly lower (paired $t$ test, $p=0.009$ ) than leaf halves dried in freeze drier $A ; \mathbf{b} B$. napus leaf tissue dried with freeze drier $B$ is deformed and darker Error bars represent standard error 


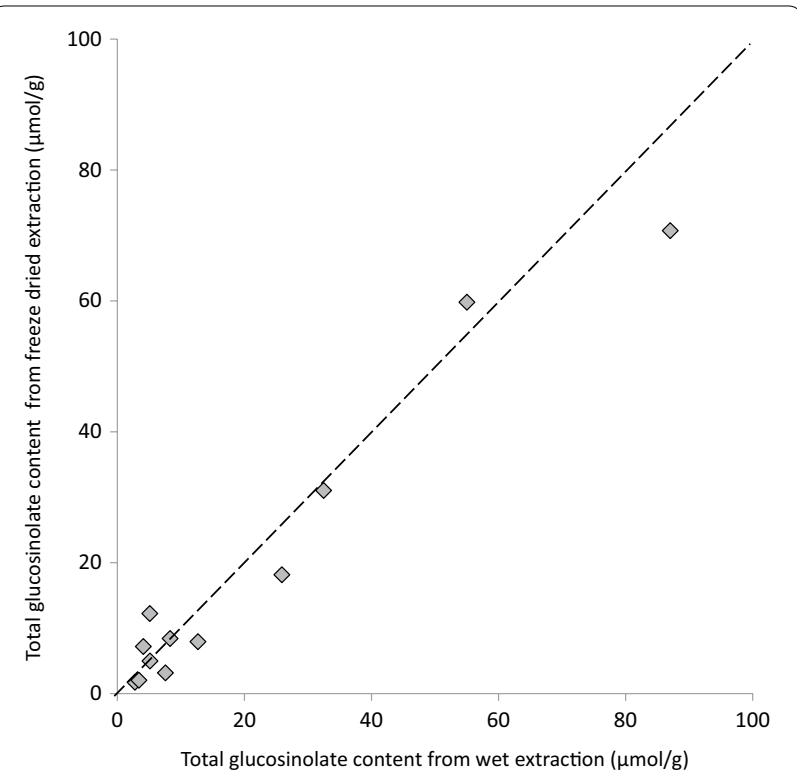

Fig. 3 There is no difference in final glucosinolate concentrations between freeze drying or direct extraction in $-20^{\circ} \mathrm{C}$ methanol. $B$. napus leaves were cut in half and frozen. One half was freeze dried prior to glucosinolate extraction, the other half was extracted directly into $-20{ }^{\circ} \mathrm{C}$ methanol $\left(n=12\right.$; paired $t$ test, $p=0.15 ; R^{2}=0.96$ ). The dashed line represents equivalence of $x$ and $y$

glucobrassicin and other indole glucosinolates. Boiling an extract in water for 10 min degrades glucobrassicin by an estimated $7 \%$.
Activity of pure myrosinase was tested at $25^{\circ} \mathrm{C}$ in water and $80 \%$ methanol solutions containing $0.25 \mathrm{mM}$ sinigrin and $0.1 \mathrm{mM}$ ascorbic acid, a myrosinase cofactor [30]. Absorbance of sinigrin at $229 \mathrm{~nm}$, at room temperature $\left(25^{\circ} \mathrm{C}\right)$, was measured over the course of an hour after myrosinase addition. Myrosinase was inactive in $80 \%$ methanol (Fig. 5) suggesting that heating methanol at $75{ }^{\circ} \mathrm{C}$ for $10 \mathrm{~min}$ in order to inactivate myrosinase may be an unnecessary step for extracting glucosinolates from plant tissue.

Glucosinolates from B. juncea, S. alba, R. sativus and $E$. sativa leaves, stems and roots were extracted (1) in boiling water for $10 \mathrm{~min}$ followed by a $4 \mathrm{~h}$ incubation at $70{ }^{\circ} \mathrm{C}$, (2) in $70 \%$ methanol at $75{ }^{\circ} \mathrm{C}$, or (3) in $80 \%$ methanol at room temperature $\left(\sim 20^{\circ} \mathrm{C}\right)$ for $30 \mathrm{~min}$ standing followed by $30 \mathrm{~min}$ shaking at $70 \mathrm{rpm}$. All extracts were centrifuged and desulfated with sulfatase according to the ISO 9167-1 method. Major glucosinolates from these species can be found in Table 5 .

Figure 6 compares glucosinolate concentrations obtained using the cold methanol method and boiling water method normalised against the ISO 9167-1 boiling methanol method. For most glucosinolates, across most tissue types and species, the three extraction methods yield similar results. We found that extraction with cold methanol produced a significantly higher estimated concentration of sinalbin in $S$. alba and sinigrin in B. juncea than the hot methanol extraction (Fig. 6). Surprisingly, given the sensitivity of glucobrassicin

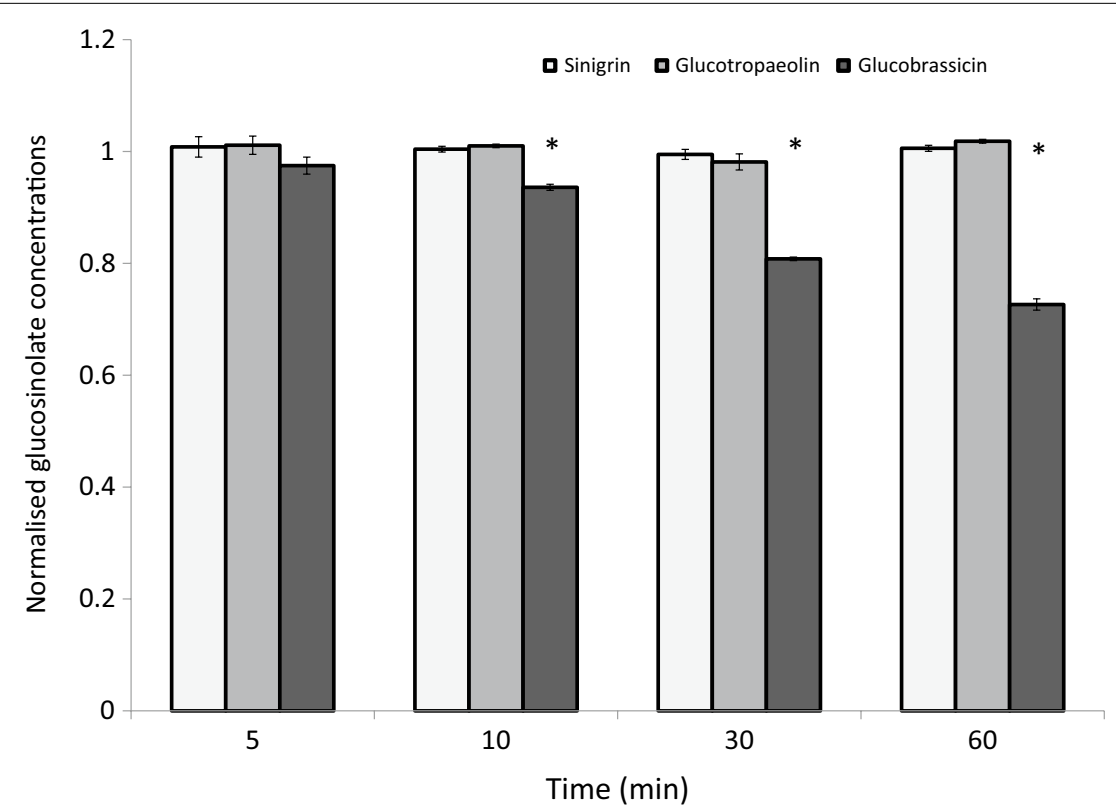

Fig. 4 Concentrations of representative aliphatic (sinigrin) and aromatic (glucotropaeolin) glucosinolates were not reduced over the course of an hour at $100{ }^{\circ} \mathrm{C}$. The representative indole glucosinolate (glucobrassicin) is degraded at $100{ }^{\circ} \mathrm{C}$. Asterisks represent significant difference from concentration at $\mathrm{t}=0$ (paired $t$ test, $p<0.05$ ) 


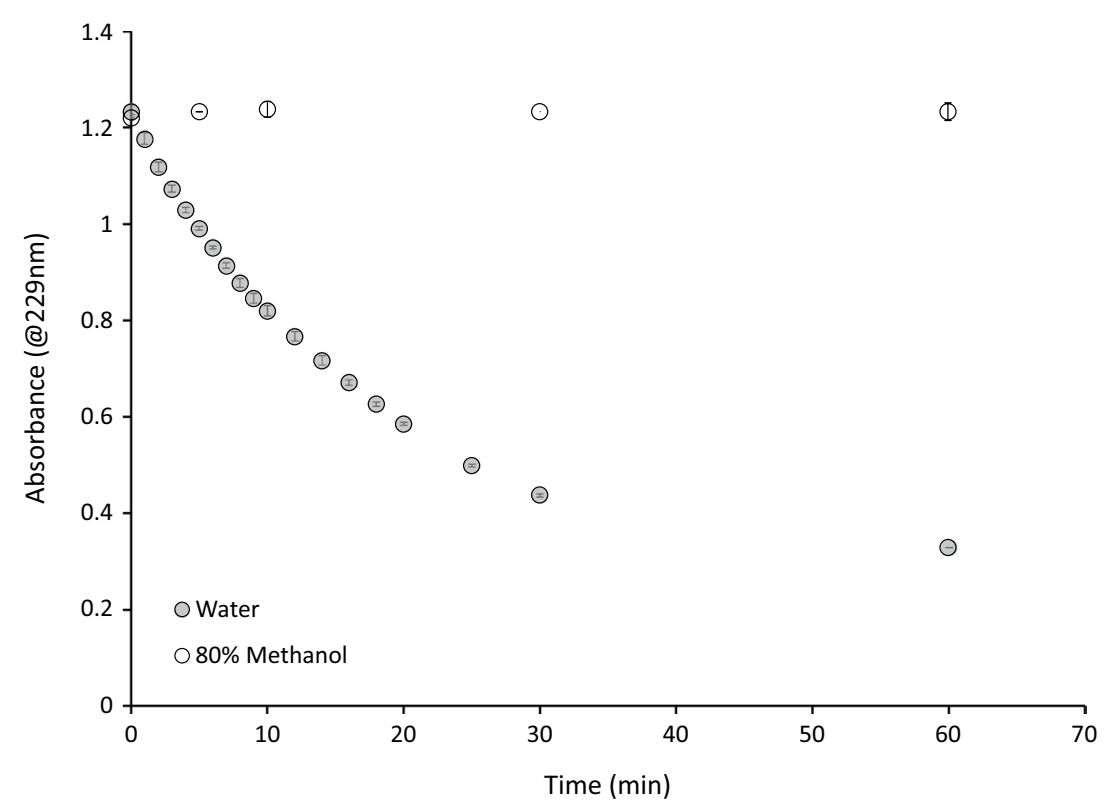

Fig. 5 Spectrophotometric analysis of sinigrin hydrolysis kinetics in water and $80 \%$ methanol $(n=3)$ by purified myrosinase $(0.05 \mathrm{mg} / \mathrm{ml})$ at room temperature $\left(25^{\circ} \mathrm{C}\right)$

Table 5 Glucosinolates examined in this study

\begin{tabular}{|c|c|c|c|}
\hline Common name & Chemical name & Structure & Species, tissue type \\
\hline Sinigrin & 2-Propenyl & Aliphatic & B. juncea $\underline{L}, \mathrm{~S}, \mathrm{R}$ \\
\hline Glucoraphenin & 4-Methylsulfinyl-3-butenyl & Aliphatic & R. sativus $L, S, R$ \\
\hline Glucoraphanin & 4-Methylsulfinylbutyl & Aliphatic & E. sativa $\mathrm{L}, \underline{\mathrm{S}}, \mathrm{R}$ \\
\hline Glucosatavin & Mercaptobutyl & Aliphatic & E. sativa $\underline{L}, \mathrm{~S}, \mathrm{R}$ \\
\hline Glucoraphasatin or hydroxyglucoerucin & 4-Methylthio-3-butenyl & Aliphatic & R. sativus $L, S, \underline{R}$ \\
\hline Glucoerucin & Methylthiobutyl & Aliphatic & $\begin{array}{l}\text { E. sativa } S, \underline{R} \\
\text { S. alba, } R\end{array}$ \\
\hline Sinalbin & 4-Hydroxybenzyl & Aromatic & S. alba $\underline{L}, \mathrm{~S}, \mathrm{R}$ \\
\hline Glucotropaeolin & Benzyl & Aromatic & S. alba $L, S, R$ \\
\hline Gluconasturtiin & Phenylethyl & Aromatic & $\begin{array}{l}\text { B. juncea } \underline{R} \\
\text { S. alba } \underline{R}\end{array}$ \\
\hline Methoxyglucobrassicin & 4-Methoxy-3-indolylmethyl & Indole & S. alba R \\
\hline
\end{tabular}

L, S and R correspond to leaf, stem and root respectively. Letters in underline represent major glucosinolates of those tissues ( $>10 \mu \mathrm{mol} / \mathrm{g} \mathrm{dry}$ weight)

to thermal degradation (Fig. 4), extraction in boiling water did not significantly reduce the concentration of the indole glucosinolate: methoxyglucobrassicin relative to the other two methods. However, glucosatavin was extracted with lower efficiency from leaves of $E$. sativa using the boiling water method (Fig. 6). It seems unlikely that this glucosinolate is less thermostable than other glucosinolates and was therefore degraded by the extraction method since reduced extraction efficiencies are not observed for stem and root samples. There are no published explanations or hypotheses that might help to explain the observed lower extraction efficiencies for glucosatavin using the boiling water method. Glucoraphasatin extraction using cold methanol appears to be significantly less effective than the standard ISO method (Fig. 6), however this was driven by poor extraction efficiencies from $R$. sativus stems (Fig. 7). Ishida et al. reported a significant $5 \%$ increase in glucoraphasatin concentrations extracted from $R$. sativus roots using the cold methanol method [23]. In this study, extraction efficiencies of glucoraphenin in $R$. sativus roots with a cold methanol method were comparable to extraction efficiencies using the boiling methanol method (Fig. 7). 


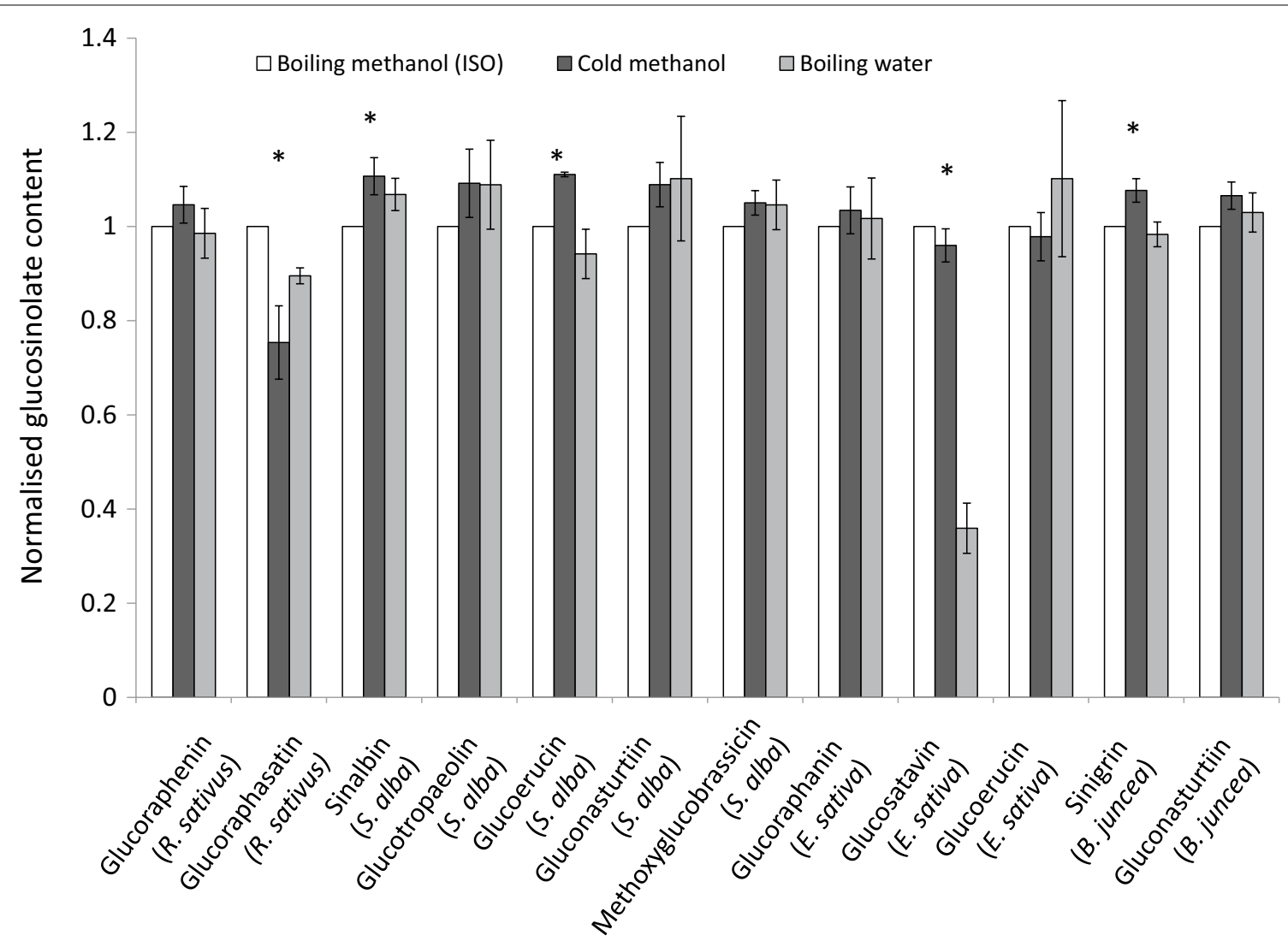

Fig. 6 Extraction of glucosinolates $(\geq 1 \mu \mathrm{mol} / \mathrm{g}$ ) in plant tissues across the three extraction methods. Glucosinolate concentrations from the cold methanol and boiling water extraction methods are normalised to the glucosinolate concentrations obtained from the ISO9167-1 $\left(75^{\circ} \mathrm{C}\right.$ methanol) method $(n=4-12)$. Error bars represent standard error. Asterisks represent a significant effect of extraction method on glucosinolate concentration (repeat measure ANOVA, $p<0.05$ )

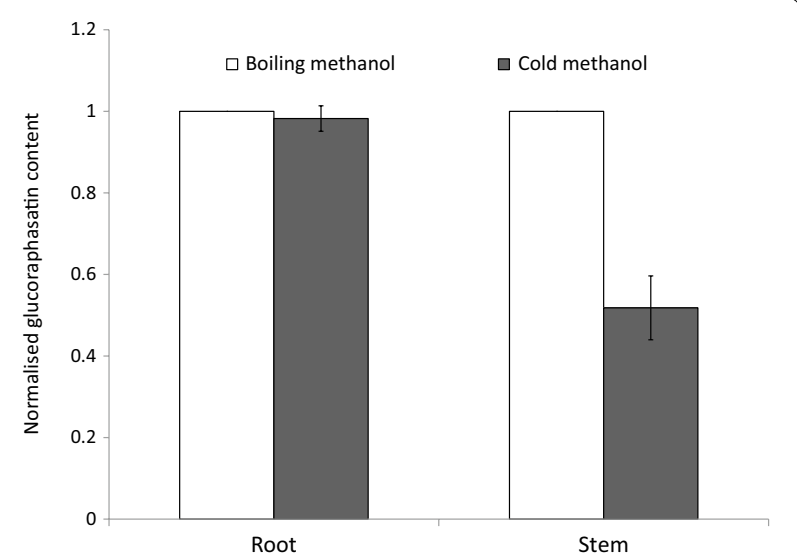

Fig. 7 The cold extraction method yields less glucoraphasatin in $R$. sativus stems relative to the ISO 9167-1 (boiling methanol) extraction method $(n=4)$. Values normalised to the ISO method results. Error bars represent standard error. Asterisks represent significant difference from the ISO 9167-1 (boiling methanol) method (paired $t$ test, $p<0.05)$
No glucosinolates were detected in a subset of samples extracted in cold water indicating the presence of active myrosinase leading to their degradation (data not shown). However, the cold methanol extraction did not significantly affect the concentration of the internal standard relative to the boiling methanol method (data not shown), providing additional evidence that myrosinase is inactivated in $80 \%$ methanol without heating (Fig. 5).

These data demonstrate that $80 \%$ cold methanol can be used instead of boiling methanol to extract glucosinolates across a broad spectrum of brassicaceae species and tissue types. With the exception of glucoraphasatin in $R$. sativus shoots, replacing hot $70 \%$ methanol with cold $80 \%$ methanol did not significantly reduce glucosinolate concentrations, yet marginally increased recovery of sinalbin in S. alba and sinigrin in B. juncea. It is advised, due to reduction in steps and hazard as well as improved or comparable glucosinolate recovery, that 
a cold methanol extraction is used instead of a boiling methanol extraction for most glucosinolate containing green tissues.

\section{Purification}

Purification of extract according to the ISO 9167-1 method is carried out by introducing $1 \mathrm{ml}$ of extract to a column containing $0.5 \mathrm{ml}$ of Sephadex solution. The column is rinsed with a $20 \mathrm{mM}$ acetate buffer at $\mathrm{pH} 4.0$ to avoid possible reduction of indole glucosinolates recovery [28]. $75 \mu \mathrm{l}$ of sulfatase solution with an activity above $0.05 \mathrm{U} / \mathrm{ml}$ is applied and left to act overnight. We tested the extraction efficiency of the ISO 9167-1 purification step at the described $\mathrm{pH} 4.0$, at $20{ }^{\circ} \mathrm{C}$ for 12,24 and $48 \mathrm{~h}$. Complete desulfation of glucosinolates in rapeseed extract required a minimum of $11 \mathrm{~h}$ in operating conditions of $30^{\circ} \mathrm{C}$ and $\mathrm{pH}$ 5.8 [25] so it was expected that an overnight $12 \mathrm{~h}$ desulfation period may be insufficient for complete desulfation of samples at room temperature. Figure 8 shows absorbance values for representative desulfoglucosinolate solutions from B. juncea, S. alba, R. sativus and E. sativa extracts treated with sulfatase solution for 12,24 or $48 \mathrm{~h}$. In most cases, 12 and $24 \mathrm{~h}$ incubation periods were insufficient for complete desulfation of glucosinolates. Glucoraphenin decreased in all $R$. sativus leaf samples tested, from 24 to $48 \mathrm{~h}$, while recovery of the internal standard increased, suggesting that specifically this desulfoglucosinolate is degraded during the purification process (Fig. 8).
Not all glucosinolates are desulfated on the column at the same rate [31], meaning that incomplete desulfation of extractions is likely to yield imprecise results: overestimating or underestimating the final concentration of glucosinolates which are desulfated quicker or slower respectively than the internal standard. In addition, relative and total concentrations of glucosinolates and degradation or rearrangement of glucosinolates during this process can also affect final concentrations [26, 31]. Use of higher sulfatase concentrations than outlined in the ISO method has been suggested for glucosinolate analysis in $B$. napus and B. oleracea $[25,31]$. Figure 9 compares relative glucosinolate concentrations from $B$. juncea, $S$. alba, $R$. sativus and E. sativa purified with a low activity sulfatase solution $(0.3 \mathrm{U} / \mathrm{ml})$ for 12,24 and $48 \mathrm{~h}$, a high activity sulfatase solution $(5 \mathrm{U} / \mathrm{ml})$ and intact glucosinolates. All concentrations have been normalised to the intact glucosinolate values. Desulfated glucosinolates concentrations obtained with high concentration sulfatase compared well with intact glucosinolates (Fig. 9). However, both high sulfatase as well as low sulfatase treatments yielded lower glucoraphenin content estimates. Coupled with the reduction of the recovery of desulfoglucoraphenin from 24 to $48 \mathrm{~h}$ (Fig. 8), these data suggest that glucoraphenin is degraded or transformed during the desulfation process.

Shorter desulfation times and lower sulfatase concentrations resulted in underestimation of the

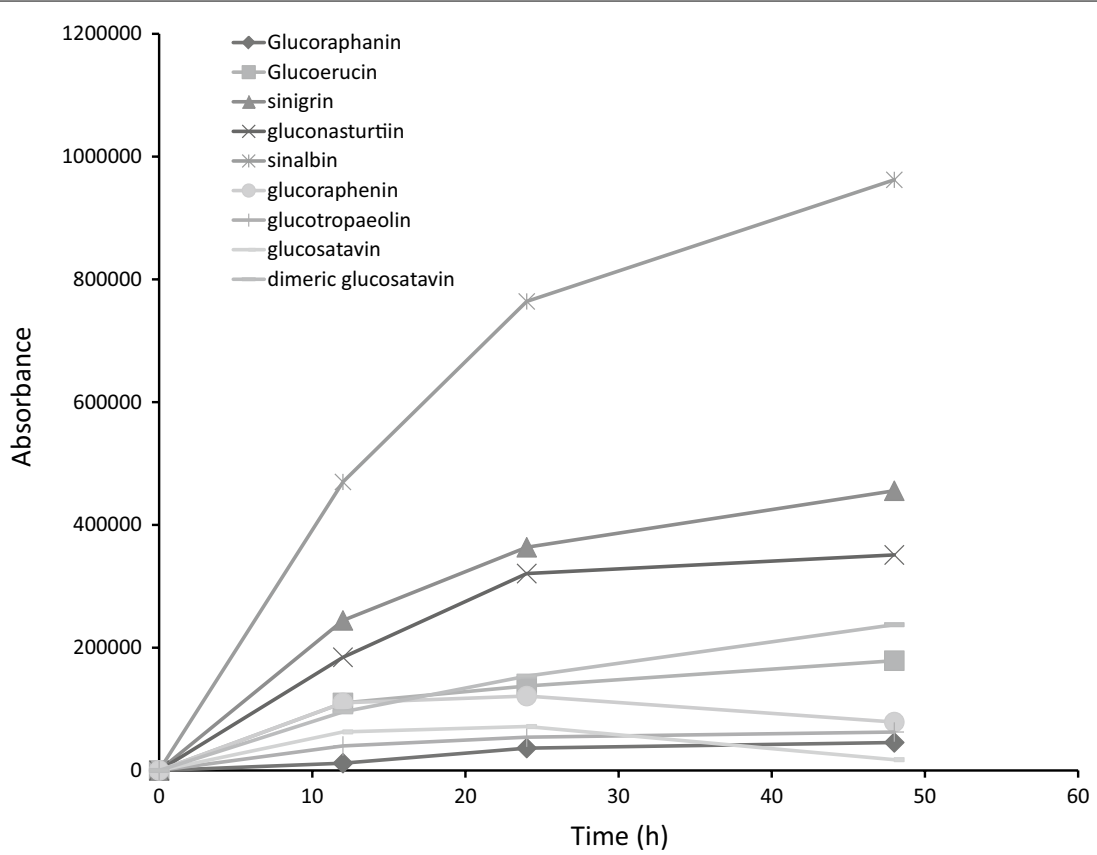

Fig. 8 Absorbance values for representative desulfoglucosinolate extracts from B. juncea, S. alba, R. sativus and E. sativa extracts treated with sulfatase solution for 12, 24 or $48 \mathrm{~h}$. These values are reflective of desulfoglucosinolate recovery and not the initial glucosinolate concentration 


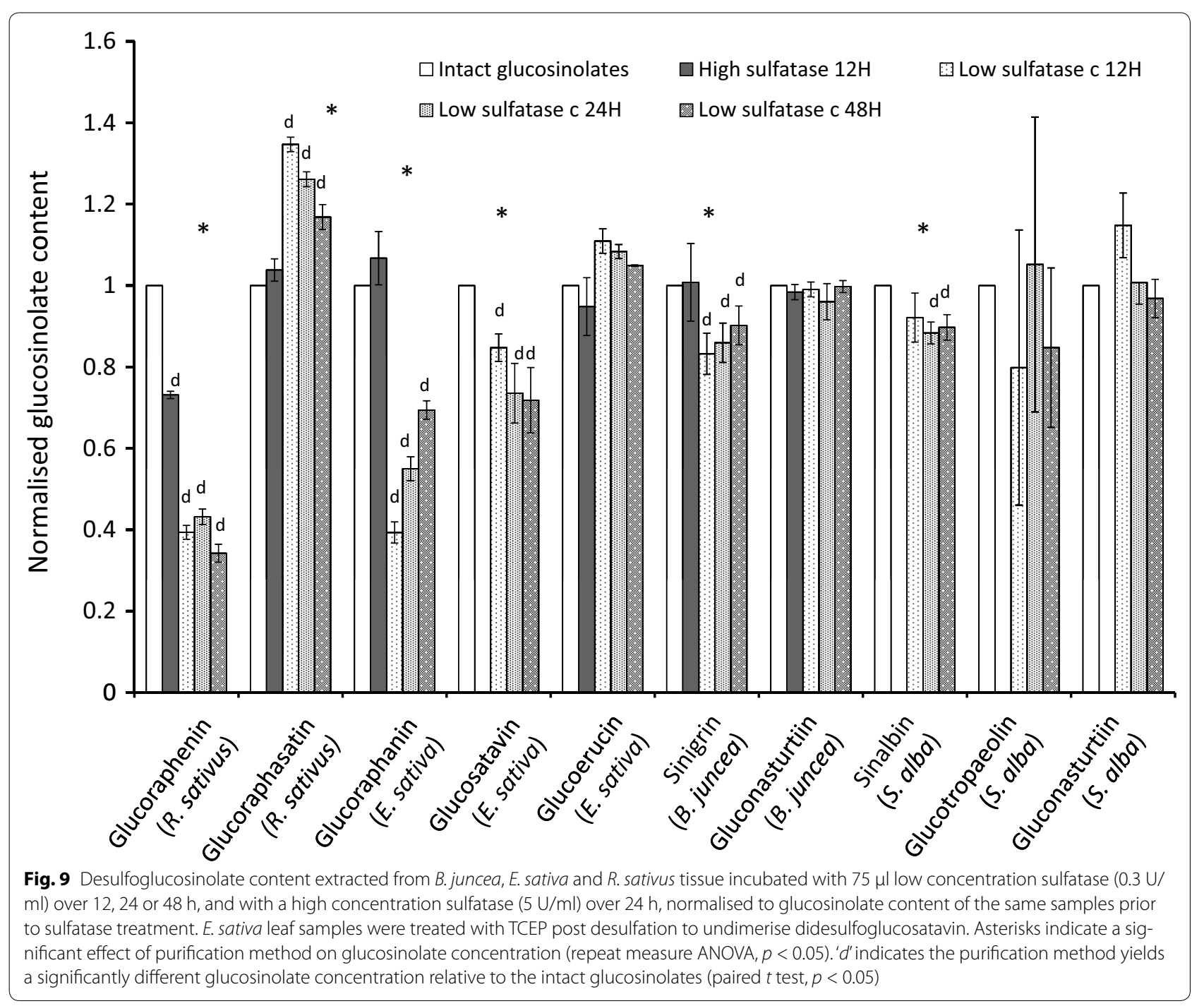

concentrations of glucoraphenin from $R$. sativus, glucoraphanin and glucosatavin from E. sativa, sinigrin from B. juncea, and sinalbin from S. alba and an overestimation of the concentrations of glucoraphasatin in $R$. sativus roots (Fig. 9). The overnight (12-24 h) incubation with $0.3 \mathrm{U} / \mathrm{ml}$ sulfatase solution yields inaccurate results for most major glucosinolates examined in this study. The ISO9167-1 method suggests that a diluted purified sulfatase solution with an activity exceeding $0.05 \mathrm{U} /$ $\mathrm{ml}$ should be used, which is shown to be insufficient for glucosinolate analysis from plant samples and conditions examined in this study (Fig. 9). Instead, if a desulfation step is carried out, use of a higher concentration of purified sulfatase (in this case, $5 \mathrm{U} / \mathrm{ml}$ ) is advised.

In all $E$. sativa leaf samples tested, recovery of monomeric desulfo-glucosatavin decreased and recovery of dimeric desulfo-glucosatavin increased between 24 and
$48 \mathrm{~h}$. Bennet et al. [22] previously hypothesised that dimeric glucosatavin is unlikely to be found in vivo and is probably an artefact of the extraction process. We can confirm that glucosatavin forms dimers as a result of the desulfation step of the extraction and that without carrying this step out and instead quantifying intact glucosinolates, no dimeric glucosatavin was detected in these samples.

Given that glucoraphenin concentration estimates are lower from methods employing a desulfation step, and that this step is also responsible for the dimerization of glucosatavin, analysis of intact glucosinolates is preferable in most instances. It is out of the scope of this study to compare or improve separation and detection methods but it should be noted that major glucosinolates in this study were accurately measured by a HPLC-UV method adapted from Herzallah and Holley [19]. For 
examination of low abundance glucosinolates, and to avoid any potential inaccuracies due to contamination it is advised that an alternative HPLC method such as those suggested in Lee et al. or Forster et al. be used instead $[26,32]$.

\section{Suggested method for glucosinolate extraction Tissue disruption}

Depending on whether freeze drying is required:

1a Freeze samples loosely wrapped in foil in liquid nitrogen and store at $-80{ }^{\circ} \mathrm{C}$. Transport samples to freeze drier in dry ice. Rapidly load samples onto a cool plate in freeze drier and ensure the pressure drops to below 5 mbar in under $2 \mathrm{~min}$. Mill samples once dried and store in airtight containers in the dark.

or

1b Freeze $50 \mathrm{mg}$ samples in liquid nitrogen in $2 \mathrm{ml}$ eppendorf tubes and store at $-80{ }^{\circ} \mathrm{C}$ (for larger samples use larger tubes). Add a volume of $80 \%$ methanol precooled to $-20{ }^{\circ} \mathrm{C}$ ensuring that final methanol concentration remains above $78 \%$ according to Eq. (1) in materials and methods. Add an appropriate volume of internal standard sinigrin or glucotropaeolin (e.g. $100 \mu \mathrm{M}$ final concentration). Disrupt tissue by adding 2 small ball bearings and agitating with a tissue lyser (e.g. tissuelyserII, Qiagen) for $10 \mathrm{~min}$ at $20 \mathrm{rev} / \mathrm{s}$. Alternatively use a plastic pestle to thoroughly grind the sample taking care that to keep the media below $0{ }^{\circ} \mathrm{C}$. Continue directly to $2 \mathrm{~b}$.

\section{Extraction}

2a For freeze dried tissue (1a). To $0.1 \mathrm{~g}$ tissue, add $5 \mathrm{ml}$ of $80 \%$ methanol and $50 \mu \mathrm{L}$ of $20 \mathrm{mM}$ sinigrin solution. Then

2b Shake sample once and leave to stand for $30 \mathrm{~min}$. Shake sample for a further $30 \mathrm{~min}(70 \mathrm{rev} / \mathrm{s})$. Centrifuge at $4000 \mathrm{rpm}$ and transfer supernatant to a fresh tube.

\section{Desulfation}

If desulfation is required, a high concentration sulfatase solution should be prepared by dissolving $15-25 \mathrm{mg}$ sulfatase in $1 \mathrm{ml} 40 \%$ ethanol and centrifuge at $8000 \mathrm{rmp}$ for $1 \mathrm{~min}$. Transfer supernatant to a fresh $2 \mathrm{ml}$ eppendorf tube and add $1 \mathrm{ml}$ of pure ethanol to precipitate the sulfatase and centrifuge at $8000 \mathrm{rpm}$ for $1 \mathrm{~min}$. Discard the supernatant and air dry the pellet before re-dissolving in $2 \mathrm{ml}$ of water. Proceed with desulfation according to ISO9167-1 method.

\section{Conclusions}

In this study we compared different methods for extracting and purifying glucosinolates from $B$. napus, B. junea, S. alba, E. sativa and $R$. sativus green tissues to highlight unnecessary or hazardous steps. We have presented a simplified method for extracting glucosinolates from plant tissues which does not require the use of a freeze drier or boiling methanol, and is therefore less hazardous, and more time and cost effective. The presented method has been shown to have comparable or improved glucosinolate extraction efficiency relative to the commonly used ISO method for major glucosinolates in the Brassicaceae species studied: sinigrin and gluconasturtiin in B. juncea; sinalbin, glucotropaeolin, and gluconasturtiin in S. alba; glucoraphenin and glucoraphasatin (roots but not shoots) in R. sativus; and glucosatavin, glucoerucin and glucoraphanin in E. sativa.

\section{Additional file}

Additional file 1. Example chromatograms of desulfoglucosinolates and glucosinolates extracted according to methods described in this manuscript.

\section{Authors' contributions}

TDA, KR, and SEH organized the project. VK carried out sample preparation and glucosinolate extractions on B. napus leaves. TDA performed all other experiments, analyzed the data, and wrote the paper; SEH, IB and KR reviewed and edited the manuscript. All authors read and approved the final manuscript.

\section{Acknowledgements}

We are grateful to Catherine Lilley, (University of Leeds), Peter Urwin (University of Leeds), Andy Barker (Barworth Agriculture Itd.) and Helen Barker (Barworth Agriculture Itd.) for collection of leaf, stem and root samples used in this study. We would also like to thank Thomas Hartley (University of York) for statistical advice. We would also like to express our gratitude to the BBSRC for funding this study. Finally, we would like to thank the reviewers for their time and effort in reviewing this manuscript.

\section{Competing interests}

The authors declare that they have no competing interests.

\section{Availability of data and materials}

Material used in this study is stored at the University of York and is available on request. Datasets analysed in this study are available from the corresponding author on request.

\section{Funding}

This work was supported by UK Biotechnology and Biology Sciences Research Council (BB/L002124/1) and (BB/K020463/1).

Received: 18 August 2016 Accepted: 11 March 2017

Published online: 21 March 2017

References

1. Clarke DB. Glucosinolates, structures and analysis in food. Anal Methods. 2010;2(4):310-25 
2. Fahey JW, Zalcmann AT, Talalay P. The chemical diversity and distribution of glucosinolates and isothiocyanates among plants. Phytochemistry. 2001;56(1):1-5.

3. Mithen RF, Dekker M, Verkerk R, Rabot S, Johnson IT. The nutritional significance, biosynthesis and bioavailability of glucosinolates in human foods. J Sci Food Agric. 2000;80(7):967-84.

4. VanEtten $\mathrm{CH}$, Daxenbichler ME, Wolff IA. Natural glucosinolates (thioglucosides) in foods and feeds. J Agric Food Chem. 1969;17(3):483-91.

5. Cartea ME, Velasco P. Glucosinolates in Brassica foods: bioavailability in food and significance for human health. Phytochem Rev. 2008:7(2):213-29.

6. Talalay P, Fahey JW. Phytochemicals from cruciferous plants protect against cancer by modulating carcinogen metabolism. J Nutr. 2001;131(11):3027S-33S.

7. Shapiro TA, Fahey JW, Wade KL, Stephenson KK, Talalay P. Chemoprotective glucosinolates and isothiocyanates of broccoli sprouts metabolism and excretion in humans. Cancer Epidemiol Biomark Prev. 2001;10(5):501-8

8. Latté KP, Appel KE, Lampen A. Health benefits and possible risks of broccoli-an overview. Food Chem Toxicol. 2011;49(12):3287-309.

9. Wiesner $M$, Schreiner M, Glatt H. High mutagenic activity of juice from pak choi (Brassica rapa ssp. chinensis) sprouts due to its content of 1-methoxy-3-indolylmethyl glucosinolate, and its enhancement by elicitation with methyl jasmonate. Food Chem Toxicol. 2014;31(67):10-6.

10. Ngala BM, Haydock PP, Woods S, Back MA. Biofumigation with Brassica juncea, Raphanus sativus and Eruca sativa for the management of field populations of the potato cyst nematode Globodera pallida. Pest Manag Sci. 2015;71(5):759-69.

11. Lord JS, Lazzeri L, Atkinson HJ, Urwin PE. Biofumigation for control of pale potato cyst nematodes: activity of Brassica leaf extracts and green manures on Globodera pallida in vitro and in soil. J Agric Food Chem. 2011;59(14):7882-90.

12. Mattner SW, Porter IJ, Gounder RK, Shanks AL, Wren DJ, Allen D. Factors that impact on the ability of biofumigants to suppress fungal pathogens and weeds of strawberry. Crop Prot. 2008;27(8):1165-73.

13. Bellostas N, Kachlicki P, Sørensen JC, Sørensen H. Glucosinolate profiling of seeds and sprouts of $B$. oleracea varieties used for food. Sci Hortic. 2007;114(4):234-42.

14. Ratti C. Hot air and freeze-drying of high-value foods: a review. J Food Eng. 2001;49(4):311-9.

15. ISO 9167-1, 1992 NA 057-05-05 AA-Joint committee of DIN and DGF for the analysis of fats, oils and products thereof, related and primary products. (2012): rapeseed-determination of glucosinolate contentpart 1: method using high-performance liquid chromatography (ISO 9167-1:1992/DAM 1:2012), German version EN ISO 9167-1:1995/prA1: 2012.).

16. Ares AM, Nozal MJ, Bernal JL, Bernal J. Optimized extraction, separation and quantification of twelve intact glucosinolates in broccoli leaves. Food Chem. 2014;1(152):66-74.

17. Church AS, Witting MD. Laboratory testing in ethanol, methanol, ethylene glycol, and isopropanol toxicities. J Emerg Med. 1997;15(5):687-92.
18. Rangkadilok N, Nicolas ME, Bennett RN, Premier RR, Eagling DR, Taylor PW. Determination of sinigrin and glucoraphanin in Brassica species using a simple extraction method combined with ion-pair HPLC analysis. Sci Hortic. 2002;96(1):27-41.

19. Herzallah S, Holley R. Determination of sinigrin, sinalbin, allyl-and benzyl isothiocyanates by RP-HPLC in mustard powder extracts. LWT Food Sci Technol. 2012;47(2):293-9.

20. Stoin DF, Dogaru RD. Researches regarding the isolation, purification and analysis of sinigrin glucosinolate from Brassica nigra and Armoracia rusticana. Bull USAMV-CN. 2007;63:77-82.

21. Oerlemans K, Barrett DM, Suades CB, Verkerk R, Dekker M. Thermal degradation of glucosinolates in red cabbage. Food Chem. 2006;95(1):19-29.

22. Bennett RN, Mellon FA, Botting NP, Eagles J, Rosa EA, Williamson G. Identification of the major glucosinolate (4-mercaptobutyl glucosinolate) in leaves of Eruca sativa L. (salad rocket). Phytochemistry. 2002;61 (1):25-30

23. Ishida M, Kakizaki T, Ohara T, Morimitsu Y. Development of a simple and rapid extraction method of glucosinolates from radish roots. Breed Sci. 2011;61(2):208-11.

24. Piekarska A, Kusznierewicz B, Meller M, Dziedziul K, Namieśnik J, Bartoszek A. Myrosinase activity in different plant samples; optimisation of measurement conditions for spectrophotometric and pH-stat methods. Ind Crops Prod. 2013;31(50):58-67.

25. Wathelet JP, Mabon N, Marlier M. Determination of glucosinolates in rapeseed improvement of the official HPLC ISO method (precision and speed). In: Proceedings of the 10th international rapeseed congress. Gosford: The Regional Institute Ltd; 1999 p. 185.

26. Förster N, Ulrichs C, Schreiner M, Müller CT, Mewis I. Development of a reliable extraction and quantification method for glucosinolates in Moringa oleifera. Food Chem. 2015;1 (166):456-64.

27. Troyer JK, Stephenson KK, Fahey JW. Analysis of glucosinolates from broccoli and other cruciferous vegetables by hydrophilic interaction liquid chromatography. J Chromatogr A. 2001;919(2):299-304.

28. Wathelet JP, Iori R, Leoni O, Rollin P, Quinsac A, Palmieri S. Guidelines for glucosinolate analysis in green tissues used for biofumigation. Agroindustria. 2004;3(3):257-66.

29. Karathanos VT, Anglea SA, Karel M. Structural collapse of plant materials during freeze-drying. J Therm Anal Calorim. 1996;47(5):1451-61.

30. Burmeister WP, Cottaz S, Rollin P, Vasella A, Henrissat B. High resolution $X$-ray crystallography shows that ascorbate is a cofactor for myrosinase and substitutes for the function of the catalytic base. J Biol Chem. 2000;275(50):39385-93.

31. Hennig K, Verkerk R, Bonnema G, Dekker M. Pitfalls in the desulphation of glucosinolates in a high-throughput assay. Food Chem. 2012;134(4):2355-61.

32. Lee JG, Bonnema G, Zhang N, Kwak JH, de Vos RC, Beekwilder J. Evaluation of glucosinolate variation in a collection of turnip (Brassica rapa) germplasm by the analysis of intact and desulfo glucosinolates. J Agric Food Chem. 2013;61(16):3984-93.

\section{Submit your next manuscript to BioMed Central and we will help you at every step:}

- We accept pre-submission inquiries

- Our selector tool helps you to find the most relevant journal

- We provide round the clock customer support

- Convenient online submission

- Thorough peer review

- Inclusion in PubMed and all major indexing services

- Maximum visibility for your research

Submit your manuscript at www.biomedcentral.com/submit 